\title{
Camouflage und die Bundestagswahl
}

\section{Camouflage and Parliamentary Elections}

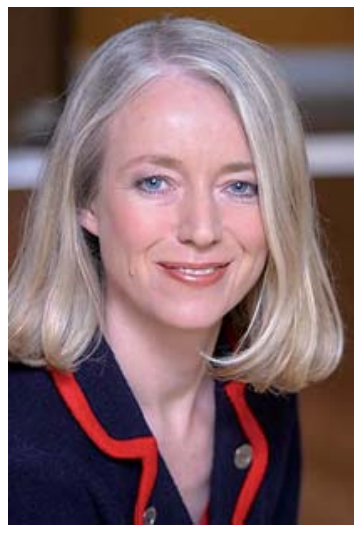

Prof. Dr. Christiane Bayerl
Vielleicht hat Sie der Paganini-Artikel am Ende des Heftes daran erinnert, dass die nächste Konzertsaison ansteht und Sie ihr Abo verlängern lassen sollten. Aufgrund der aktuellen Aktivitäten in den Medien drängte sich mir noch eine andere Verknüpfung auf, nicht nur Musik und Haut, sondern Politik und Haut:

In der Politik ist es wie im Konzert: Ungeübte Ohren halten schon das Stimmen der Instrumente für Musik.

Amintore Fanfani

Fanfani war kein Musiker und spielte auch nicht Fanfare. Er war ein Nachkriegspolitker und ab 1945 Mitglied der Democrazia christiana. In den Folgejahren war er Ministerpräsident und Kabinettsmitglied und engagierte sich für staatlichen Wohnungsbau und Sozialreformen. Das oben zitierte „Stimmen der Instrumente“ dringt auch gerade an unsere Ohren. Im kabarettistischen Bereich werden wir durch die reichlich mit Camouflage bestückte „Kunst“-Figur des Wahlkandidaten Horst Schlämmer, den Hape Kerkeling darstellt, auf die heiße Phase der Bundestagswahl „eingestimmt“.

Der aus dem Französischen stammende Begriff Camouflage umfasst Irreführung, Täuschung und Tarnung. Da ich diesen Artikel mit dem Hinweis auf einen virtuosen Musiker begonnen habe, mag mancher ja nach seinem Musikgeschmack die Gedanken weitergesponnen haben und vielleicht an die deutsche Band Camouflage denken, z.B. den Song „Love is a shield to hide behind,..."; oder vielleicht an Stan Ridgway, den US-amerikanischen Musiker und Lead-Sänger der Band Wall of Voodoo, der 1986 die Single Camouflage hoch in den Charts platzierte.

Die Camouflagefarben aus der Tierwelt beim Chamäleon, bei Faltern und anderen Spezies kennen wir. Sozialpsychologisch versteht man unter Camouflage eine Technik der Abwehr. Der Einsatz des boden- und waldfarbenen Camouflage-Designs beim Militär unterstützt das Nicht-Sichtbar-Sein, das Verstecken. Andererseits wird dieses Design auch immer mal wieder als Safari-Stil auf den Laufstegen der Modemetropolen präsentiert - in diesen Fällen nicht um zu verstecken. Dicke Make-up-Schichten, wie wir sie von den Nofretete-Abbildungen kennen, dienten zwar nicht der Abwehr, aber doch der Abgrenzung vom gemeinen Volk, das sich dergleichen nicht leisten konnte. Camouflage-Make-up-Produkte werden im Tanzsport, bei Oper, Schauspiel und Ballett, bei manchem Braut-Make-up und beim Fotoshooting für Wahlplakate eingesetzt - auch nicht, um den Kandidaten/in zu verstecken. Am dicksten trägt der Spaßkandidat Horst Schlämmer Camouflage auf, schichtweise - um sich damit zu zeigen und zu unterhalten.

Camouflage ist im dermatologischen Sinne ein stärker deckendes Make-up, lang haltend und resistent. Wir setzen es ein zum Kaschieren von Keloiden, Naevi flammei, Hämangiomen, Couperose, Rosazea, dunklen Augenringen, Melasma, Vitiligo, Tätowierungen, frischen OP-Narben, direkt nach Laserungen und vielem mehr. Nicht ganz klar ist mir, warum Camouflage sich in vielen Lehrbüchern nicht findet. Beim Vorbereiten eines Vortrags zu Camouflage suchte ich verschiedene Inhaltsverzeichnisse dermatologischer Lehrbücher ab. Im Stichwortverzeichnis findet sich das Schlagwort Camouflage nicht. Selbst in einigen dermatokosmetischen deutschen und englischsprachigen Bänden sucht man vergebens. Allerdings wird in den neuen Leitlinien zu Akne eine Stellungnahme zu Camouflage enthalten sein. Der dermatologischen Camouflage gebührt eine Rehabilitierung. Es ist nichts Ehrenrühriges daran einen Makel zu verdecken, wenn das unseren Patienten hilft, sich wieder frei zu bewegen.

Christiane Bayerl, Wiesbaden
DOI 10.1055/s-0029-1215174

Akt Dermatol 2009; 35; 371

(c) Georg Thieme Verlag KG .

Stuttgart · New York

ISSN 0340-2541

Korrespondenzadresse

Prof. Dr. med. Christiane Bayerl

Klinik für Dermatologie und

Allergologie, HSK,

Wilhelm-Fresenius-Klinik GmbH

Städtisches Klinikum Wiesbaden

Lehrkrankenhaus der

Universität Mainz

Aukammallee 39

65191 Wiesbaden

christiane.bayerl@hsk-wiesbaden.de 